citation analysis, authorship analysis, and collaboration indicators. The publication trends and characteristics of the included articles/journals will be assessed, including, where possible, funding bodies' characteristics. Any association between these characteristics and the level of research productivity/output will be evaluated.

Result/Conclusions This study will identify time-periods where, UK-based, OE publications volume had been high/low, and provide insights into $\mathrm{OE}$ research contribution to cancer epidemiology, and its strengths and weaknesses compared with PHE. The identified time-periods will be the focus of a subsequent phase, documentary review, where $\mathrm{OE}$ challenges/facilitators will be examined compared to those in PHE.

\section{A NETWORK OF OCCUPATIONAL RISK EXPERTS FOR EVALUATION OF UNUSUAL WORKPLACE HEALTH EVENTS}

${ }^{1} \mathrm{G}$ G Gault, ${ }^{2}$ Provost, ${ }^{2}$ Lauzeille, ${ }^{2}$ Buisson, ${ }^{2}$ Imbernon, ${ }^{3}$ Rolland, ${ }^{4}$ Valenty. ${ }^{1}$ Bordeaux, France; ${ }^{2}$ Institute for Public Health Surveillance, Occupational Health Department, Saint-Maurice, France; ${ }^{3}$ Institute for Public Health Surveillance, Alerts and Regions Coordination Depart, Bordeaux, France; ${ }^{4}$ Département Santé au travail, Institut de Veille Sanitaire, Saint Maurice, France

\subsection{6/oemed-2013-101717.22}

Background The French Institute for Public Health Surveillance (InVS) monitors the health status of the population according to all health determinants, including occupational risks.

Since several years, we noted an increased number of unusual workplace health events notified to InVS but also to other stakeholders (occupational medicine consultations, Labour Ministry, etc.).

A network of occupational risk experts at local level was implemented by InVS with the aim to organise the evaluation and the investigation of unusual workplace health events with a prompt and consensual response.

Methods The network is composed of a Labour medical inspector, an occupational physician of the hospital consultation, and two trained epidemiologists of InVS.

The regional office of InVS coordinates the network and informs the experts when an unusual occupational health event is notified to the local health emergency platform.

A prompt telephone meeting based on first information about the event allows the experts to assess the signal, and to come to a consensual decision about its validation, and further investigations.

Results The first network was implemented in 2008 in the region of Aquitaine (South West France). Since, eight other French regions are involved.

Several signals have been analysed, mostly cancers clusters and sick building syndromes. The networks allowed to validate unusual events and to highlight relation with occupational environment. In some cases, the networks proposed some recommendations on prevention and control measures.

With several examples, the authors show how this network works, its added value and the limitations of epidemiological workplace investigations.

Conclusion The result of the experimentation of this network was positive. Demonstrated added value of this network was a rational response leading to better reactivity, accuracy and efficiency when treating the signal, and potential detection of emergent problems.
23 THE BURDEN OF DISEASE FROM OCCUPATIONAL EXPOSURES

R Driscoll. University of Sydney, Australia

10.1136/oemed-2013-101717.23

Objectives To present the main results from the GBD2010 study in terms of the burden of disease arising from occupational risk factors.

Methods As part of the GBD 2010 project, the burden of disease from occupational risk factors was estimated. These risk factors and conditions were a range of carcinogens; asthmagens; vapours, gases, dusts and fumes (causing COPD); asbestosis, silicosis and coal workers' pneumoconiosis; ergonomic exposures leading to low back pain; injuries and occupational noise (leading to hearing loss). The primary methodology used involved estimating the population attributable fraction by estimating exposure prevalence and identifying appropriate relative risks. Some other estimation approaches were also used.

Results The key results of the work will be presented and discussed.

Conclusions Work-related exposures result in a substantial burden of ill health in workers. The results identify exposures and exposure settings that should be looked at when prioritising interventions.

\section{PRACTICE AND QUALITY OF WORK CAPACITY EVALUATIONS: A SURVEY AMONG SWISS PSYCHIATRISTS}

${ }^{1} S$ S Schandelmaier, 'Bachmann, ${ }^{1}$ Kedzia, ${ }^{2}$ Fischer, ${ }^{1}$ Kunz, ${ }^{1}$ de Boer. ${ }^{1}$ University Hospital Basel, Basel, Switzerland; ' University of Applied Sciences, Olten, Switzerland

\subsection{6/oemed-2013-101717.24}

Objective Psychiatric expertises for determining a person's work capacity are being criticised in Switzerland. Issues of concern are lack of transparency and variation in the judgment on work capacity. The aims of this study were (1) to learn about current practice among Swiss psychiatric experts in evaluating and reporting on work capacity, (2) to compare the practice to professional guidance, and (3) to identify sources for the variation and lack of transparency that may be amenable to improvement. Methods National online survey among psychiatrists experienced in evaluation of work capacity. We identified issues of concern through the literature and discussion with opinion leaders in psychiatric expertises. We inquired current practice of disability evaluation, aspects of quality, and suggestions for improvement.

Results 129 psychiatrists participated (response rate 31\%). The job description, reference for determining work capacity in the current job, was perceived as mandatory information by $90 \%$, but was usually missing or deficient in files (74\%). The psychiatrists expressed work capacity as free text plus percentage of work capacity $(49 \%)$, percentage only $(23 \%)$, or free text only (14\%). 13\% used instruments to report on work capacity. Psychiatrists reported diverse interpretations for 'percentage of work capacity'; three interpretations were reported as applicable in equal frequency around $80 \%$. Psychiatrists usually used report forms of the insurers (77\%), peer consulting (65\%), and process guidelines (51\%), but rarely evidence-based information. Current guidelines attach low importance to job descriptions and instruments, and recommend percentage of work capacity' without reflecting the pros and cons. 